\title{
Análise de Controvérsias no Campo da Saúde Mental a partir de uma Pesquisa-Intervenção: Para uma Política dos Fazeres em Campos de Saberes Heterogêneos
}

\author{
Vanessa Maurente \\ Pontifícia Universidade Católica Do Rio Grande do Sul \\ Porto Alegre, RS, Brasil \\ Grace Vali Freitag Tanikado \\ Cleci Maraschin \\ Universidade Federal do Rio Grande do Sul \\ Porto Alegre, RS, Brasil
}

\begin{abstract}
RESUMO
A partir do referencial foucaultiano e institucionalista, este artigo busca analisar uma experiência de construção de um sítio na internet com uma equipe de Saúde Mental localizada em um antigo hospital psiquiátrico de Porto Alegre. A pesquisa-intervenção objetivou por em evidência os desafios e controvérsias do trabalho efetuado pela equipe em relação às formas de cuidado em saúde mental. As análises realizadas destacaram as controvérsias advindas de discursos de bases epistemológicas distintas em relação às concepções de cuidado em saúde mental. Conclui-se que o desencontro de posições epistemológica pode não ser impeditivo para um trabalho em equipe desde que exista uma política dos fazeres capaz de gerar, em ato, coletivos de ação.
\end{abstract}

Palavras-chave: Saúde mental; Pesquisa-intervenção; Política dos fazeres.

\section{ABSTRACT}

Analysis of Controversies in the Field of Mental Health from a Research-Intervention: Searching a Doing Policy in the Heterogeneous Knowledge Fields

Based on a foucaudian theoretical framework and an Institutional Analysis approach, this article aims to analyze the experience of building a website with a Mental Health team located in a former psychiatric hospital in Porto Alegre/ Brazil. The intervention-research metodology was used to highlight the challenges and controversies of the team's everyday work in relation to the way they deal with mental health care while they are engaged in the website creation. The analyzes showed that the controversies arising from distinct epistemological foundations of discourse related to the different mental health care conceptions. We conclude that the mismatch of epistemological positions can not be an impediment to an interdisciplinary teamwork if there is a doing policy able to generate, in action, collective objects to deal with.

Keywords: Mental health; Participatory research; Doing policy.

\section{RESUMEN}

Análisis de las Controversias en el Ámbito de la Salud Mental de una Investigación-Acción: en Busca de una Politica de los Haceres en Campos de Saberes Heterogeneos

Este artículo se sostiene en el pensamiento foucaultiano y en la perspectiva institucionalista para abordar una experiencia de la construcción de un sitio web por un equipo de Salud Mental ubicado en un antiguo hospital psiquiátrico en Porto Alegre. La investigación participante puso en evidencia los desafíos y controversias del trabajo realizado por el personal en relación con las distintas formas de atención en salud mental. Los procesos de analisis resaltan las controversias que surgen de los discursos de bases epistemológicas distintas con relación a las formas de atención en la salud mental. Se concluye que la falta de coincidencia de las posiciones epistemológicas puede no ser un impedimento para el trabajo en equipo si hay una política de los hechos que pueden generar, en acto, la acción colectiva.

Palabras clave: Salud mental; Investigación participante; Interdisciplinariedad. 


\section{INTRODUÇÃO}

Um dos princípios do Sistema Único de Saúde consiste no trabalho em equipe fundado na interdisciplinaridade, que difere da multidisciplinaridade e transdisciplinaridade. De acordo com Couto, Schimith e Araújo (2013), a multidisciplinaridade consiste em um trabalho conjunto entre diferentes disciplinas, sem a construção de um método comum a elas. A transdisciplinaridade corresponde à transposição dos limites disciplinares e à tomada dos objetos de conhecimento a partir de uma complexidade que ultrapassa saberes constituídos. Por sua vez, a interdisciplinaridade corresponde à tomada de consciência de que nenhuma disciplina dá conta isoladamente de uma problemática e é necessário que se integrem saberes, a fim de alcançar maior resolutividade dos problemas. O trabalho interdisciplinar em saúde permite que se pense o sujeito a partir da lógica da integralidade, na qual os aspectos orgânicos, psíquicos, sociais e políticos se entrelaçam em uma complexidade inerente. A separação de tais aspectos se dá no plano científico disciplinar com o objetivo de simplificar para explicar, mas acaba por mostrar a insuficiência do trabalho isolado das disciplinas. Nosso interesse neste trabalho é avaliar como seria possível a constituição de coletivos que produzam ações efetivas com suas diferenças.

O campo da saúde mental é marcado pela sobreposição de práticas e discursos com bases epistemológicas distintas. O movimento de reforma psiquiátrica produziu uma polarização nesses discursos que podem ser identificados como: 1) o da patologização do indivíduo, que tem como consequência a descrença em sua capacidade de autonomia e defende a instituição hospitalar psiquiátrica como principal referência para os cuidados com a loucura e 2) o da emancipação do sujeito com sofrimento psíquico, que busca a saúde mental a partir da inserção social e construção de autonomia. Com inúmeras variações, que não caberiam neste artigo, estes discursos apresentam noções de sujeito, de saúde e de tratamento que se contrapõem.

Tem-se como fato um tanto naturalizado que essas contradições no campo da saúde mental conduzem para rupturas nos processos de comunicação, dificuldades na articulação de um trabalho interdisciplinar e na compreensão do sujeito a partir da lógica da integralidade. Entretanto, pode-se considerar que essa heterogeneidade de saberes é capaz de criar condições de possibilidade para a construção de outros fazeres. Desse modo, propomos abrir uma pequena fresta entre saberes e práticas levando a pensar que práticas efetivas não nascem necessariamente da fabricação de consensos, mas que controvérsias podem contribuir para a constituição de práticas coletivas com bom grau de efetividade. Frente a isso, se justificam os estudos que analisem as contradições que marcam as formas de compreensão e tratamento do sofrimento psíquico, considerando a processualidade inerente a este campo. Além disso, é fundamental que sejam criados espaços de produção coletiva de fazeres junto a equipes de trabalho em saúde mental nos quais essas diferenças possam ser explicitadas e trabalhadas.

Este artigo apresenta relatos de uma pesquisaintervenção realizada junto a unidade de internação infantil e adolescente de um antigo hospital psiquiátrico da cidade de Porto Alegre. Tais oficinas utilizaram dispositivos tecnológicos, propondo a construção de um sítio na internet do serviço pelos trabalhadores da equipe técnica - psicólogos, psiquiatras, assistentes sociais, pedagoga e educador físico. O principal objetivo era propor uma atividade compartilhada e, através dela, explicitar os saberes e fazeres da equipe e a modulação dos mesmos no trabalho realizado.

Apresentamos, a seguir, uma breve análise da constituição do campo da saúde mental, fundamental para a composição do olhar que lançamos sobre as análises realizadas. Em seguida, percorremos as linhas de constituição do serviço como parte do Hospital Psiquiátrico, assim como a experiência das oficinas tecnológicas. Por fim, apresentamos as ressonâncias das controvérsias constitutivas do campo da saúde mental na produção realizada na oficina, assim como a atualização destas controvérsias em novas práticas e discursos que incidem sobre o trabalho do serviço. As análises nos permitem pensar os modos de trabalhar em equipe no campo da saúde mental.

\section{A SAÚDE MENTAL ENQUANTO CAMPO HETEROGÊNEO DE DISCURSOS E PRÁTICAS}

A compreensão do que designamos momentaneamente como campo da saúde mental remete a processos históricos aqui analisados a partir do modelo genealógico proposto por Michel Foucault. De acordo com este autor (2011), a genealogia se constitui em uma forma de história capaz de dar conta da constituição dos saberes, dos discursos e dos domínios de objeto. Seria discutir, historicamente, como se produzem efeitos de verdade no interior dos discursos que não são em si nem verdadeiros nem falsos. Para Foucault (2011), a genealogia se opõe à pesquisa da origem histórica, pois, procurar tal origem seria querer tirar todas as máscaras para desvelar uma identidade primeira. $\mathrm{O}$ autor coloca que "é preciso se libertar de todo um jogo de noções 
que diversificam, cada uma à sua maneira, o tema da continuidade" (Foucault, 2012, p. 23).

Ao nos referimos ao campo da saúde mental, as primeiras análises apontam para o fato de que a loucura é mais antiga que as práticas de internação e as experiências em relação a ela são distintas em diferentes contextos históricos. De acordo com Foucault (2010), até o início do século XVII, o louco era recebido com familiaridade, como alguém que vinha de outro mundo, um ser fascinante que anunciava um saber proibido sobre as trevas, o fim do mundo, a felicidade última, o castigo supremo. Entretanto, esse saber do louco não tinha um comprometimento com a verdade, mas era o "castigo de uma ciência desregrada e inútil" (Foucault, 2010, p. 25).

Por outro lado, já naquele século, a loucura também passa a ser considerada no universo do discurso como algo que nascia no coração dos homens, dirigindo sua conduta. De acordo com Foucault (2010), para esta visão, ainda que a loucura fosse sábia, teria que inclinar-se diante da ciência para a qual ela era loucura. Esta posição foi designada como uma consciência crítica da loucura. O início do Renascimento teria sido marcado pela co-existência desta consciência crítica e da experiência trágica anterior. Entretanto, segundo Foucault (2010), este período de "encontros" não durou muito e o sistema que fazia da loucura uma experiência no campo da linguagem, onde o homem era confrontado com sua moral, suas regras e sua verdade, colocou em segundo plano as figuras trágicas.

Apesar de até então a loucura não estar relacionada à internação, desde a Idade Media já existiam estruturas destinadas a manter afastados certos grupos sociais. Os leprosários eram um exemplo de segregação medicamente justificada que ficaram sem utilidade no final da Idade Média, em função do desaparecimento da doença no mundo ocidental. Tais estruturas que, de acordo com Foucault (2010), ficaram esvaziadas por dois séculos, serão retomadas no século XVII, mantendo as mesmas práticas de exclusão, porém com funções renovadas. Eles passam a ser habitados por um conjunto heterogêneo de sujeitos - mendigos, prostitutas, inválidos, desempregados e loucos - que tinha em comum a não inserção no trabalho. Enquanto os leprosários tinham uma função especialmente médica, os novos Hospitais Gerais tinham significações políticas, religiosas, econômicas e sociais. Um salto à atualidade, permite verificar que os movimentos de desinstituionalização de alguns levam à institucionalização de outros, tal como ocorre no serviço em questão no qual o vínculo com as drogas passou a ser o motivo preponderante de internação (Scisleski, 2007).
De acordo com Foucault (2010), foi numa certa experiência do trabalho que se formulou a exigência econômica e moral do internamento. Os Hospitais Gerais foram uma das respostas dadas pelo século XVII à crise econômica que afetava o mundo ocidental. A internação, neste período, designava o momento decisivo em que a loucura passava a ser percebida no horizonte social da pobreza, da incapacidade para o trabalho e da impossibilidade de se integrar socialmente. E se ela ainda parecia vir de outro lugar, é porque atravessava, "por conta própria, as fronteiras da ordem burguesa, alienando-se fora dos limites sacros de sua ética" (Foucault, 2010, p.74).

A questão que se coloca neste artigo diz respeito ao fato de que a consciência da loucura nunca foi um conjunto único e fechado, mas sempre surgiu simultaneamente em pontos múltiplos, formando construções capazes de mudar o rumo dos acontecimentos. De acordo com Foucault (2010) enquanto na maior parte das outras formas de saber se percebe uma convergência, nas experiências em relação à loucura a divergência se inscreveria nas estruturas, "só autorizando uma consciência da loucura já rompida, fragmentada, desde o início, num debate que não se pode concluir" (Foucault, 2010, p. 167).

A série de acontecimentos designada como o nascimento da psiquiatria toma Phillippe Pinel como principal personagem e atribui a ele o papel mítico de tirar os grilhões dos loucos, que eram acorrentados juntos aos criminosos nas instituições francesas até então. Entretanto, a participação de Pinel no processo de consolidação da psiquiatria se deu pelas reformas que fez em relação ao tratamento dado aos alienados nestas instituições e pelas suas inúmeras publicações, que buscavam uma descrição clínica/nosográfica e a proposição de uma prática terapêutica para as doenças mentais. Do mesmo modo, segundo este autor, a versão de que Pinel seria o pai da psiquiatria se legitimou apenas pela posição política e cultural que a França ocupava no panorama mundial da época, na medida em que este médico havia sido precedido por muitos, em outros países, que buscavam descrever a loucura como uma especialidade da medicina. Além disso, a história da psiquiatria necessitava de um ícone que centralizasse o discurso moral e humanitário característico do período que antecedeu a construção dos asilos de alienados, e a figura de Pinel serviu muito bem para compor este enredo.

Após a segunda guerra mundial as condições de residência e trabalho se encontravam comprometidas em escala global. A impossibilidade de reinserção laboral de veteranos de guerra na Europa produz um aumento da população nos hospitais psiquiátricos. Este 
fenômeno teve como consequência o questionamento em relação às possibilidades que estas instituições tinham de assegurar os direitos humanos e estar em consonância com os novos princípios de reconstrução de sociedades livres. Junto a isto, iniciam-se nos Estados Unidos, na Escócia, na França e, principalmente, na Itália, movimentos que negavam a função terapêutica dos hospitais psiquiátricos, entendendo-os como lugares de produção de sofrimento psíquico (Evaristo, 2000). Neste novo paradigma, as instituições manicomiais eram vistas como espaços de apagamento da complexidade do sujeito pela normatização e exclusão, que estrategicamente deixavam sob custódia situações sociais sem saída.

De forma lenta e descontínua, algumas modificações concretas se esboçavam neste período. Nos Estados Unidos, J.F. Kennedy promulgou o Community Mental Helth Act, estabelecendo centros psiquiátricos alternativos e territorializados. Na Inglaterra e Escócia, surgiram as comunidades gestionadas por psicóticos com apoio da iniciativa privada e a Comunidade Terapêutica de Maxwell Jones. Na França, foram criados setores psiquiátricos nos hospitais gerais e os primeiros serviços de apoio territorializados. Entretanto, de acordo com Yasui (2011), foi somente na Itália que, nesta ocasião, a crítica ao modelo de internação em manicômios culminou num movimento que resultou na extinção dos hospitais psiquiátricos.

No Brasil, os primeiros movimentos de desinstitucionalização chegam em 1992, quando é aprovada no estado do Rio Grande do Sul a Lei da Reforma Psiquiátrica (Lei Estadual no 9.716, 1992) que determina a substituição progressiva dos leitos nos hospitais psiquiátricos por uma rede de atenção integral em saúde mental, redefinindo as regras de proteção aos sujeitos em sofrimento psíquico e restringindo as condições de internações compulsórias. Esta lei marca o início de uma série de reformulações nas políticas de atenção à saúde mental, buscando a substituição dos hospitais psiquiátricos, compreendidos como locais de exclusão e reprodução de doença mental, por serviços integrais que visem não apenas tratar o sofrimento psíquico, mas reinserir socialmente os sujeitos com longas internações.

Entretanto, estas propostas encontram fortes resistências no cenário brasileiro. As reformulações nas políticas públicas de saúde não se restringem à saúde mental, mas sim ao modelo de atenção organicista e hospitalocêntrico há muito instituído e ainda hegemônico. As novas diretrizes do Sistema Único de Saúde (Lei Federal no 8080, 1990) propõem a integralidade no cuidado e, junto a isso, a necessidade de construção de espaços interdisciplinares. Assim, cresce um sentimento de indefinição dos papéis dos núcleos - assim chamados em contraponto ao campo interdisciplinar (Nunes et al. 2010). Esta relativização dos limites entre as profissões da saúde produz tensões nas equipes que têm como resultado a oscilação entre ações corporativistas de classes profissionais, que muitas vezes se consolidam pela desqualificação do trabalho dos colegas, e a urgência em tornar possível um diálogo entre saberes e fazeres, em sua maioria, fundados sobre bases epistemológicas distintas.

Nesse campo de contradições as práticas e saberes se sobrepõem, mais do que se interligam. A questão não está na quantidade de disciplinas que podem dar conta de um objeto do conhecimento, mas na própria tomada de algo como objeto de diferentes áreas. O sujeito dos manuais de psiquiatria não parece ser o mesmo "usuário do serviço de saúde mental”. Algo parecido ocorre com a noção de loucura. Foucault (2010) busca desconstruir a noção de que a loucura seria um objeto permanente e, assim, o que se modificaria seria o conhecimento que se tem dela, como a psiquiatria sustenta - afirmando que não apenas a percepção da loucura se transformou ao longo dos séculos, mas que as próprias estruturas destas experiências não se mantiveram as mesmas. Desta forma, saímos da posição perspectivista para assumir a multiplicidade de modos de existência dos objetos.

\section{AS FORMAS DE PESQUISAR}

A forma de conhecer e intervir colocada em ação neste trabalho foi a pesquisa-intervenção, justamente em função de sua possibilidade de acompanhar a processualidade dos contextos colocados em análise e produzir ações junto aos coletivos que compartilham semelhante problemática. A pesquisa-intervenção se configura como um delineamento de pesquisa a partir de experiências brasileiras, principalmente na Psicologia Social. Marisa Rocha e Katia Aguiar (2010) retomam a trajetória de sua conformação, apresentando a influência da pesquisa-ação de Kurt Lewin que, mesmo apresentando características funcionalistas, trazia o questionamento da objetividade da pesquisa e indicava que o pesquisador também produzia diferença por sua presença no campo de pesquisa. Esta forma de pesquisar chega à América Latina nos anos de 1960 e tem sua ação transfomada, sendo utilizada em projetos de emancipação social e com objetivos de autogestão. No encontro com o movimento institucionalista francês, da década de 1960, e latino-americano, das décadas seguintes, a pesquisa-ação se conforma em pesquisa-intervenção, ganhando contornos de intervenção socioanalítica. 
O processo de formulação da pesquisa-intervenção aprofunda a ruptura com os enfoques tradicionais de pesquisa, ampliando as bases teórico-metodológicas das pesquisas participativas. Sua proposta é de atuação transformadora da realidade sociopolítica, através de intervenções de ordem micropolítica na experiência social. Podemos pensar na radicalização da ideia de interferencia na relação sujeito - objeto pesquisado, considerando que essa interferência não se constitui em uma dificuldade própria às pesquisas sociais, em uma subjetividade a ser superada ou justificada no tratamento daquilo que se constitui como dado, mas como condição ao próprio conhecimento (Paulon \& Romagnoli, 2010).

Outra importante produção com a pesquisaintervenção é realizada por um conjunto de pesquisadores que tem trabalhado com a cartografia, método proposto por Gilles Deleuze e Félix Guattari, como operador dessa forma de pesquisa. Nesse campo, destacamos Kastrup (2009). Segundo a autora, a cartografia se dedica ao estudo da dimensão processual da subjetividade e de seu modo de produção, não possuindo um conjunto de regras prontas a serem aplicadas, mas que exige uma construção ad hoc, na habitação do território investigado e através da implicação do pesquisador no trabalho de campo.

A análise de implicação é uma das ferramentas fundamentais da pesquisa-intervenção e se constitui no exercício de análise do pesquisador, considerando a impossibilidade de uma neutralidade (Lourau, 2004). Nesta experiência que vivemos, colocamos em questão nossa participação como pesquisadoras em alguns momentos, dado que muitas vezes experimentávamos junto aos trabalhadores do serviço de saúde mental as lógicas manicomiais que iam de encontro aos pressupostos da Reforma Psiquiátrica, com os quais nos alinhamos. Um exercício constante de análise de implicação ocorreu durante o processo de pesquisa, possibilitando a confluência de uma intervenção e produção de conhecimento em diálogo com essa posição política e ética.

Elegemos como forma de intervenção a oficina, modalidade de trabalho em grupo que se dedica a produção de algo coletivamente - nesse caso, de um sitio da internet do próprio serviço de Saúde Mental em questão. Segundo Passos (2012), a oficina potencializa os saberes de todos seus participantes, borrando os papéis pré-determinados (tais como professor-aluno, pesquisador-objeto de pesquisa, etc), possibilitando a emergência de uma produção coletiva. Interessa, portanto, a oficina como modalidade de intervenção pois coloca em primeiro plano os fazeres, a construção coletiva de algo. Como forma de registro das atividades no campo de pesquisa, utilizamos o diário de campo, ferramenta útil na busca dos analisadores que compõem a discussão e resultados deste estudo.

$\mathrm{Na}$ seção seguinte são abordados processos de constituição do local no qual realizamos o projeto aqui mencionado. Posteriormente, apresentamos relatos da intervenção realizada, na qual os trabalhadores do local foram convidados a produzirem o sítio do serviço.

\section{PROCESSOS DE CONSTITUIÇÃO DO SERVIÇO DE SAÚDE MENTAL}

O Centro no qual realizamos a pesquisa aqui apresentada se configura como um serviço que atua na modalidade de internação e de ambulatório, contando com uma equipe interdisciplinar. Sua constituição é marcada por acontecimentos diversos e contraditórios. Nos anos de 1999 e 2000 Ministério Público move ações contra o estado do Rio Grande do Sul responsável pelo Hospital Psiquiátrico - alegando que este local não cumpria os princípios do Estatuto da Criança e do Adolescente (ECA) ao não ter um espaço diferenciado para a internação de jovens. Espaços para internação de crianças já existiam desde a década de 1970, atendendo a população oriunda do interior do estado, assim como um ambulatório especializado no atendimento de crianças, destinado à população do território no qual o hospital estava inserido (Scisleski, 2007). Devido a esta ação, em 2001, o atendimento a crianças e adolescentes no Hospital sofre modificações.

$\mathrm{O}$ acordo firmado entre o Estado e o Ministério Público para a construção de um serviço para o atendimento de crianças e adolescentes recomendava a constituição de uma estrutura seguindo a legislação regulamentadora do atendimento em saúde mental vigente à época. Em ambas as esferas, estadual e federal, as premissas que baseavam a legislação eram da Reforma Psiquiátrica, através da Lei Estadual $n^{\circ}$ 9716/92 (1992) e da Lei Federal no 10216/01 (2001). Assim, o serviço é criado para ser um Centro de Atenção Psicossocial, constituindo-se como CAPS. Para a montagem desse serviço é composta uma equipe por profissionais oriundos do serviço de internação para crianças e do ambulatório - ambos já existentes -, além de técnicos contratados especialmente para este fim. Naquele momento não havia ainda legislação que normatizasse exatamente a organização e função dos CAPS.

Porém, em 2002, o Ministério da Saúde, através da Portaria $n^{\circ} 336$ (2002), regulamenta o funcionamento dos CAPS, deixando clara sua atuação como serviço substitutivo à internação psiquiátrica. Segundo a portaria, o CAPS deve atender a pessoas ligadas ao 
território em que o serviço está inserido e não pode estar situado no mesmo espaço físico que os estabelecimentos hospitalares psiquiátricos. Define, ainda, o recadastramento dos serviços já organizados como CAPS a partir de parecer técnico do Ministério da Saúde.

A partir da regulamentação destas características, o Centro não pode mais denominar-se como CAPS, pois não se enquadra nessas definições. Além de fazer parte da estrutura do hospital psiquiátrico, seguia o atendimento a públicos diferenciados, antes prestados pelo serviço de internação - interior do estado e pelo ambulatório - vizinhanças do hospital, na capital. Scisleski (2007) comenta que à época dessa modificação os trabalhadores do serviço buscaram apoio do hospital para organizá-lo de forma que pudesse ser credenciado como um CAPS, conforme a nova legislação, o que acabou por não se concretizar. Em 2005, então, o serviço deixa de utilizar a sigla CAPS e outro nome similar é escolhido. Os diferentes discursos sobre os modos de compreender o sofrimento psíquico e intervir nesta área se materializam no campo da saúde mental. Aqui, trata-se de um serviço situado em um hospital psiquiátrico que é atravessado pelo movimento da reforma psiquiátrica. Entretanto, observamos as mesmas contradições em Centros de Atenção Psicossociais, nos quais práticas manicomiais são articuladas em função da inércia inerente ao campo, assim como da formação em algumas áreas, que tende a ser predominantemente crítica em relação ao movimento antimanicomial.

As marcas do desejo de que o serviço atuasse como um CAPS, presente em uma parte da equipe, podem ser vistas nos esforços em direção do Centro em direção ao fortalecimento de um trabalho ambulatorial, assim como das oficinas terapêuticas. Entretanto, tais iniciativas se contrapõem ao modo de atuar predominante em um hospital, que é a internação. Desse modo, algumas das práticas permanecem pautadas pela lógica do hospital psiquiátrico, materializando o discurso asilar através do controle e isolamento dos usuários e foco na individualização dos problemas ao próprio usuário e a sua rede familiar próxima. Cabe ressaltar que a condição social de vida dos jovens é marcada pela pobreza, violência, abandono e enfraquecimento das redes de convivência. Entretanto, essas contingências são pouco consideradas, uma vez que as categorias nosográficas atribuídas aos jovens advém, todas, de um mesmo manual internacional de classificação. Esse modo de operar no campo da saúde mental apresenta relações com as análises que Foucault faz a respeito do nascimento das casas de internação, quando a loucura passa a ser percebida no horizonte da pobreza, na incapacidade de participar da vida "social".
Nessa conjuntura, os "transtornos mentais" acabam se confundindo com os "desvios de conduta". O estudo de Scisleski, Maraschin e Silva (2008), realizado com jovens, mostra que estes chegam ao serviço em questão, em sua maioria, através de percursos de marginalidade social, muitos através de encaminhamentos judiciais. Segundo as autoras, a forma de subjetivação que toma a experiência dos jovens em condições de vida fragilizadas como delinquência, infração e doença mental estanca-lhes as possibilidades de saída deste ciclo de exclusão social ao mesmo tempo em que, paradoxalmente, o Hospital Psiquiátrico fica compreendido como um local de ressocialização pelo tratamento moral. Esta é mais uma das formas pelas quais as práticas se confrontam. Diferentes tipos de "loucura" recebem o tratamento moral (da exclusão) desde Pinel, ao mesmo tempo em que o espaço é atravessado por diversas lutas entre as áreas da saúde e pelas transformações sócio-históricas que instituem novas formas de sofrimento psíquico.

\section{PRODUÇÕES EM CAMPO: OFICINA DO SÍTIO}

Iniciamos o projeto de pesquisa-intervenção participando das reuniões semanais da equipe técnica do serviço, composta por assistentes sociais, enfermeiro, terapeutas ocupacionais, médicos clínicos, médico neurologista, médico foniatra, médicos psiquiatras, psicólogos, psicopedagogos e educador físico, em função de outras atividades do projeto que mantínhamos anteriormente no Hospital. Nestas reuniões, observamos que, ao falarem sobre o serviço, os trabalhadores traziam uma heterogeneirdade de posições. Como já realizávamos oficinas de construção de blogs com os usuários, propomos a criação, junto a equipe, um site para "apresentar" o serviço.

Organizamos, em reuniões com a equipe, a forma como a oficina do sítio iria funcionar: oito encontros de duas horas com os seis técnicos que se interessaram em participar e os pesquisadores, no laboratório de informática do serviço. Nos primeiros encontros, o objetivo foi apenas propiciar uma experimentação com a as ferramentas de criação do sítio. A partir disso, iniciou-se a discussão sobre como apresentar o serviço. Esta discussão levou ao planejamento do que deveria estar na página e de que forma. Para a apresentação neste artigo, selecionamos algumas das discussões que tensionam a simultaneidade de modelos de cuidados em saúde mental que se produziram no percurso das oficinas.

Os dois primeiros encontros foram de familiarização com os recursos para construção de páginas web. No 
terceiro encontro, os trabalhadores definiram a estrutura do sítio: além da página inicial, haveria onze páginas, que falariam da história do serviço, apresentariam as atividades e a organização do trabalho. Ao discutir a página inicial, surge a questão se haveria ou não uma imagem. Todos concordam que sim, mas que imagem seria? O diálogo que se produziu tensionou o espaço que o serviço ocupa no Hospital Psiquiátrico e é parte do diário de campo de uma das pesquisadoras:

“- A foto dos prédios históricos do Hospital.

- Mas não temos nada a ver com aquilo! Nós estamos aqui, não lá!

- Não, somos parte do Hospital, aqueles são prédios do Hospital, todo mundo conhece.

- Não, somos outra coisa.

- Mas tem que ter uma foto da entrada, então da entrada daqui.

- Ah, da entrada daqui. É dai, sim.

- Quem sabe produções dos pacientes? Um mural bem grade produzido por eles? Fotos das oficinas?"

Uma das oficineiras sugere uma composição de fotos e todos parecem concordar:

“- Sim, uma composição! Fotos dos trabalhos dos pacientes, da entrada, dos prédios do hospital!”

O diálogo anterior revela a resistência de parte da equipe para identificar-se com a imagem do histórico hospital. O que, por um lado, pode apontar o distanciamento de uma lógica asilar, de outro, pode explicitar algumas das dificuldades do ambulatório em dar continuidade ao seu trabalho, uma vez que a necessidade de distanciamento e autoreferência também parecia operar relação à rede de serviços do território. Não somente a relação com o fora do serviço, mas também os modos internos de trabalho foram objeto de conversa.

Esses modos apareciam, por exemplo, na definição do zoneamento dos espaços, questão presente em diversos pontos da construção do sítio. Um momento que ilustra a intensidade dessa discussão foi a definição do local que cada atividade do serviço internação, ambulatório, oficinas - ocuparia no sítio. No planejamento "Ambulatório" vinha antes de "Internação". Alguns profissionais se opuseram a isso, dizendo que a internação deveria vir antes. Uma trabalhadora, então, contestou, dizendo que o ambulatório deveria ser apresentado primeiro, pensando num leitor que busca atendimento no local. Os outros insistiram, dizendo que o serviço é, de fato, uma unidade de internação, não um ambulatório e afirmando: "Eu entendo o que tu pensas, que o ambulatório deve ser o primeiro recurso terapêutico, mas nós somos mais internação, é isso que está no projeto, que nos faz conhecidos". Alguém disse, ainda: " $A$, de ambulatório, vem antes de I, de internação". Ao que se respondeu: "nós não somos um CAPS, somos uma unidade de internação".

É interessante constatar que embora existam controvérsias relativas ao que vem primeiro, se internação ou ambulatório, existia um compartilhamento de trabalho nos dois tipos de serviços, embora a ênfase do trabalho fosse localizada na internação. Também cabe considerar que a distinção estabelecida pela equipe para caracterizar as duas grandes modalidades de seus fazeres não se afasta da lógica hospitalar.

Na página dedicada à "Internação" foi primeiramente feita a descrição das atividades de cada área, o que gerou inúmeras discussões. As atividades descritas foram lidas por todos os participantes e feitas algumas modificações: "Se a área X diz que faz entrevista com familiares, eu também vou colocar isso, porque eu também faço". "Fulano não faz isso sempre... será que tinha que estar aí?". "Eu faço o grupo $X$, tem que estar ali". A parte das definições do que faz cada profissional é, então, renomeada como "informações complementares", localizada em um novo hyperlink na página da Internação.

Cabe salientar que, tanto na página da internação, quanto na que apresenta a equipe, os trabalhadores escolheram se identificar pela área de atuação e não pelos nomes próprios. A questão da nomeação é sempre um fator problemático para a instituição. Esse foi um tema abordado em outro trabalho (Maurente e Maraschin, 2014) no qual analisamos a controvérsia tratada com o Comitê de Ética em Pesquisa pelo fato das crianças e adolescentes utilizar o nome próprio para firmar a autoria de suas produções. Em tal ocasião foi argumentado que associar o nome de uma pessoa a uma instituição psiquiátrica não consistia em uma boa referência tendo em vista o estigma da loucura. Pelos extratos, podemos supor que essa associação refletia também em seus trabalhadores.

Para finalizar o trabalho, os profissionais participantes da oficina apresentaram sua produção a toda equipe. Foi um encontro ruidoso, animado. $\mathrm{O}$ arquivo com a página foi colocado em todos os computadores do laboratório de informática. Os participantes da oficina mostraram a produção com apropriação, em pequenos grupos em torno dos computadores. Os colegas prestaram atenção, lendo os textos. Foram feitas diversas sugestões de alteração, principalmente em relação às descrições de atividades. Uma das trabalhadoras, que não participou do grupo, afirmou: 
"nós fazemos muito mais coisas. A descrição que está no serviço de educação fisica (planejar, executar, avaliar ações...) é que deveria estar na enfermagem. Tem o acompanhamento 24 horas!". A partir de discussões como a desse ponto, envolvendo o conjunto de técnicos, o grupo que participou da oficina realizou as alterações sugeridas e finalizou uma versão inicial do sítio. Como observamos nesse extrato e no depoimento mais acima, a comparação entre as atividades desenvolvidas, quando tratada de modo disciplinar, gerou competição. Por outro lado, a construção da página do sítio gerou um coletivo interessado, que juntamente com as controvérsias, conseguiu chegar a um resultado que foi aprovado pelo conjunto dos trabalhadores. Parece ficar claro que existem fazeres que têm possibilidade de potencializar encontros e constituir coletivos de ação e outros, fazeres disciplinares, que produzem competição. Uma questão de análise é que tipo de fazeres no serviço poderiam ser experimentados da mesma forma que a construção do sítio?

Iniciou-se, então, a busca por espaços para a publicação da página. A coordenação do serviço procurou a direção do Hospital para relatar a experiência de construção do sítio e encaminhar a autorização para a publicação. Naquele momento, a informação dada pela direção do Hospital é de que a publicação estava autorizada, não havendo necessidade de que ela fosse apresentada ou analisada. A coordenadora relata que ouviu a seguinte frase: "confio no trabalho de vocês".

O Hospital possui uma página institucional hospedada dentro do portal da Secretaria da Saúde SES. A coordenação do serviço, então, iniciou contatos com a SES a fim de utilizar este espaço. Participamos de uma reunião com o responsável pelo portal do Hospital, que informou que a página do serviço não poderia ser publicada tal como havia sido produzida, já que o portal da SES possuía uma pré-configuração de alguns elementos. Acertou-se, assim, que a página seria publicada seguindo o formato padrão, mas com o conteúdo produzido pela equipe. Passamos os arquivos do sítio para o técnico da SES. Alguns dos participantes demonstraram decepção pela não publicação da versão que eles haviam produzido.

Na página da SES, o sítio do serviço, ficou localizado como uma das unidades de internação do Hospital, mesmo tendo atividades em outras modalidades de atendimento. $\mathrm{O}$ conteúdo que apresenta o trabalho ambulatorial não foi publicado prontamente, sendo necessária a negociação da coordenação do serviço com o técnico da SES para isso. Ainda, algumas seções não foram publicadas, tais como a que apresenta as parcerias do Centro, e os créditos pela construção da página, bem como a que descreve as atividades de ensino localizadas dentro do serviço. Esta última foi suprimida após um pedido de um departamento que gerencia estas atividades no Hospital, alegando que aquelas ações eram exclusivas de sua atuação. Vemos repetindo-se em um âmbito maior - nas relações entre o centro e o próprio hospital - aquilo observado entre os diversos setores de especialidades no serviço, conforme descrito acima.

\section{POLÍTICAS DOS FAZERES}

A análise apresentada neste artigo diz respeito às relações entre os modo de pensar e operar no campo da saúde mental decorrentes das diferentes posições que convivem nos serviços, colocando em questão a necessidade de um pensamento único para se produzir fazeres efetivos no trabalho das equipes. Não se trata, certamente, de operar uma disjunção entre saberes e práticas mas um certo deslocamento criativo, no sentido de inventar práticas como tecnologias da produção de coletivos que possam fecundar os próprios saberes e constituir novos fazeres.

Vimos que existem diferentes saberes que constituem o campo da saúde mental. Os aportes teóricos mencionados (Foucault, 2011) apontam para o fato de que as formas de expressão e compreensão da loucura não se mantiveram as mesmas ao longo da história, mas estiveram pautadas por exigência sociais, econômicas, políticas, religiosas e científicas. A partir da modernidade, com o advento do capitalismo e da apropriação do trabalho pela moral, a experiência da loucura passa a ser vista no horizonte da pobreza, o que se reedita hoje no serviço no qual esta pesquisa foi realizada, quando a maioria das crianças e adolescentes chegam à internação via percursos de marginalidade social, sendo, muitos deles, por medida judicial, decorrentes de seu vínculo com o uso e tráfico de drogas.

Cabe salientar que esta forma de compreender a "loucura" se materializa atualmente em intervenções de caráter higienista, como a transformação da medida de internação compulsória de usuários de crack em política pública, proposta através do Projeto de Lei $n^{\text {o } 3365 / 2012 ~(2012) . ~ A ~ i d e i a ~ t e m ~ c o m o ~ j u s t i f i c a t i v a ~ a ~}$ declaração de que o uso do crack faz com que o sujeito adquira um comportamento nocivo contra si mesmo e contra a sociedade. Trata-se de uma intervenção do Estado que não reconhece as origens socioeconômicas do problema e se utiliza de um discurso científico igualmente individualizante para legitimar sua implementação. O isolamento do usuário de crack e a abstinência durante o período de internação, tiram-no da circulação urbana, mas não dão conta das condições de vida que contribuíram para o abuso de drogas. Do 
mesmo modo, a falta de uma rede de atenção à saúde mental substitutiva ao hospital psiquiátrico, impede que este sujeito retome um tratamento após a internação, o que implica, na maioria das vezes, em reincidência. Sendo assim, desde o nascimento do capitalismo, as práticas relativas à loucura se renovam, mas mantém os mesmo objetivos: servir a um modelo econômico ou a uma sociedade idealizada por este modelo e não ao sujeito em sofrimento psíquico.

O que produz controvérsias no campo da saúde mental atualmente é a convivência entre práticas como a internação compulsória, a patologização da pobreza e a manutenção de hospitais psiquiátricos como principal recurso para a crise, por um lado, e a legislação criada a partir dos movimentos sociais que culminaram na regulamentação dos princípios do SUS (Lei Federal no 8080, 1990) e na Reforma Psiquiátrica, por outro. Estas formas não se excluem mas, ao contrário, co-existem nos serviços de saúde. Nossa indagação consistiu precisamente no fato de como constituir um trabalho em equipe habitando essas controvérsias e não necessariamente promovendo uma guerra epistemológica entre as mesmas? No caso da pesquisa-intervenção realizada as disputas emergiam quando a ênfase disciplinar era tomada como medida de qualificação do trabalho e era despotencializada quando os trabalhadores focavam a construção do sítio. Desse modo, a produção de um sítio na internet para apresentar o trabalho funcionou como uma tecnologia de relação, potencializando a produção sem acobertar as diferenças mas, ao contrário explicitando-as.

No que tange ao trabalho interdisciplinar, as análises da produção do sítio apontam para movimentos de articulação e desarticulação entre as áreas. Movimentos observáveis, por exemplo, no momento em que os profissionais escrevem, separadamente, o que faz cada um; ou quando manifestam coincidências nos afazeres: "Se a área X diz que faz entrevista com familiares, eu também vou colocar isso, porque eu também faço". As diretrizes do SUS preconizam o trabalho interdisciplinar que busca abordar o sujeito em sua integralidade (Lei Federal $n^{\circ}$ 8080, 1990). Sendo assim, coloca-se a necessidade de articulação das ações. O que parece ter sido evidenciado na análise realizada é que um trabalho interdisciplinar pode ser favorecido no momento em que a equipe produz coordenação das ações com vistas a um projeto comum, no caso o sítio. No momento em que direcionamos o esforço interdisciplinar somente para o plano conceitual permaneceremos estimulando um conhecer-sobre, que reforça o já posto em cada disciplina. Ao agregarmos a esse sabe-sobre um saber-como, ou seja, os saberes advindos dos modos de fazer-com abrimos brechas para a criação e para a autoria coletiva, como demonstra a experiência com a construção do sítio. Apesar destas questões serem, na maioria das vezes, conhecidas pelos profissionais da saúde mental atualmente, a construção de trabalhos de pesquisa-intervenção permite que se desdobrem novas análises para trabalhadores, que muitas vezes têm seu cotidiano afogado pelo excesso de tarefas e pelas barreiras nos processos comunicacionais. A proposta de construção coletiva de um sitio que apresentasse o serviço como um todo teve a função de tensionar os desencontros entre discursos e práticas no local, na medida em que se tornava necessário criar coordenações entre as ações de profissionais com distintas concepções. Além disso, permitiu ressignificações sobre o contexto experienciado, na medida em que as discussões foram sendo realizadas. Os demais participantes da equipe, que não participaram das oficinas, também puderam compor os debates, no momento em que a página foi apresentada na reunião geral do serviço.

Cabe salientar que os diferentes discursos e práticas que se materializam no funcionamento institucional ultrapassam as relações entre os sujeitos que compõem o espaço, sendo articulados nas normas do hospital e da Secretaria Estadual de Saúde. Isto pode ser observado quando os participantes tentaram publicar a página da SES e tiveram que adequar seu formato ao modelo já utilizado de modo generalizado pela Secretaria, tendo, também, o conteúdo modificado (os serviços ambulatoriais foram excluídos das informações). Este fato permitiu novas análises a respeito do funcionamento institucional no qual as estratégias de abertura para o cuidado - o ambulatório - são apagadas ou percebidas como pouco importantes. Neste sentido, a construção de espaços de discussão, compartilhamento de experiências e produção coletiva de sentidos e de criação de novos fazeres características da pesquisa-intervenção, podem ser de fundamental importância neste campo. No momento em que existem contradições, existem também as possibilidades para a invenção de novas práticas, o que pode ser potencializado por estratégias de pesquisa que buscam produzir movimentos nos contextos nos quais trabalham.

\section{REFERÊNCIAS}

Brasil. (1990). Lei Federal $n^{\circ} 8080$ de 19 de setembro de 1990. Dispõe sobre as condições para a promoção, proteção e recuperação da saúde, a organização e o funcionamento dos serviços correspondentes e dá outras providências. Brasilia, 1990. Recuperado em 20 mar. 2014 de http://www.planalto.gov. br/ccivil_03/leis/18080.htm.

Brasil. (1990). Estatuto da Criança e do Adolescente. Lei Federal 8069/1990. Recuperado em 16 mar. 2014 de http://www. planalto.gov.br/ccivil_03/leis/18069.htm. 
Brasil. (1992). Lei Estadual n 9.716, de 07 de agosto de 1992 que dispõe sobre a Reforma Psiquiátrica no Rio Grande do Sul. Ministério da Saúde. Legislação em Saúde Mental: 1999-2004. Brasília, 2005. Recuperado em 19 mar. 2014 de http://portal.saude.gov.br/portal/arquivos/pdf/Legislacao.pdf.

Brasil.(2001). Lei Federal $n^{\circ} 10.216$ de 06 de abril de 2001. Dispõe sobre a proteção e os direitos das pessoas portadoras de transtornos mentais e redireciona o modelo assistencial em saúde mental. In: Ministério da Saúde. Legislação em Saúde Mental: 1999 - 2004. Brasília, 2005. Recuperado em 20 mar. 2014 de_http://portal.saude.gov.br/portal/arquivos/pdf/Legislacao. pdf.

Brasil (2002). Portaria do Ministério da Saúde $n^{\circ} 336$ de 19 de fevereiro de 2002. Dispõe sobre os Centros de Atenção Psicossocial. Brasília. Recuperado em 15 mar. 2014 de http:// portal.saude.gov.br/portal/arquivos/pdf/Portaria\%20GM\% 20336-2002.pdf.

Brasil. (2012). Projeto de Lei $n^{\circ} 3365$ de 07 de março de 2012. Altera o art. 29 do Decreto-Lei $n^{\circ} 891$, de 1938, que prevê a possibilidade de internação compulsória de dependentes de drogas ou álcool. Brasilia, 2012. Recuperado em 24 mar. 2014 de http://www.camara.gov.br/proposicoesWeb/prop mostrarinte gra;jsessionid $=$ CE67D69EF95B39DDB3B044421345C52B.no de1 codteor $=968002 \&$ filename $=P L+3365 / 2012$.

Couto, L., Schimith, P., \& Araújo, M. (2013). Psicologia em ação no SUS: interdisciplinaridade posta à prova Psicol. cienc. prof. (Brasília), 33(2). Recuperado em 14 ago. 2014 de http://www. scielo.br/scielo.php?pid=S1414-98932013000200018\&script $=$ sci arttext.

Dias, R. O (2011). Pesquisa-intervenção, cartografia e estágio supervisionado na formação de professores. Fractal, Rev. Psicol., 23(2), 269-289.

Evaristo, P. (2000). Psiquiatría y salud mental. Trieste: Asterios Editore.

Foucault, M. (2010) A história da loucura na idade clássica. São Paulo: Perspectiva.

Foucault, M. (2011). O sujeito e o poder. In: D. Hubert \& P. Rabinow. Foucault: uma trajetória filosófica. Rio de Janeiro: Forense Universitária

Foucault, M. (2012). Microfisica do poder. Rio de Janeiro, Graal.

Kastrup, V. (2009). O funcionamento da atenção no trabalho do cartógrafo. In: E. Passos, V. Kastrup, \& L. Escóssia (Orgs.). Pistas do método da cartografia: pesquisa-intervenção e produção de subjetividade. Porto Alegre: Sulina.
Lourau, R. (2004). Objeto e método da análise institucional. In S. Altoé (Org.). René Lourau: analista institucional em tempo integral (pp. 66-86). São Paulo: Hucitec.

Maurente, V.S., Maraschin, C. (2014). Pesquisa-intervenção e ética: a proteção da identidade dos participantes e a necessidade da devolução do conhecimento produzido. In D. J. Francisco, \& L. Santana. Problematizações éticas em pesquisa. Maceió, Edufal.

Nunes, E., Ferreto, L., Oliveira, A., Nascimento, J., Barros, N., \& Castellanos, M. (2010). O campo da Saúde Coletiva na perspectiva das disciplinas. Ciência e Saúde Coletiva, 15(4), 1917-1922.

Passos, E. (2012) A oficina como tecnologia de coprodução. In A. L. Palombini, C. Maraschin, \& S. Moschen. Tecnologias em Rede: oficinas de fazer saúde mental (pp. 167-172). Porto Alegre: Sulina.

Paulon, S. \& Romagnoli, R. (2010) Pesquisa-intervenção e cartografia: melindres e meandros metodológicos. Estudos e pesquisas em psicologia (UERJ, Rio de Janeiro), 10, 85-102.

Rocha, M. L. \& Aguiar, K. F. (2010). Entreatos: percursos e construções da psicologia na rede pública de ensino. Estudos e pesquisas em psicologia (UERJ, Rio de Janeiro), 10, 85-102.

Scisleski, A. (2006). "Entre se quiser, saia se puder": o percurso dos jovens pelas redes sociais e a internação psiquiátrica. Dissertação de Mestrado. Programa de Pós-Graduação em Psicologia Social e Institucional. Universidade Federal do Rio Grande do Sul, Porto Alegre.

Scisleski, A., Maraschin, C., \& Silva, R. N. (2008). Manicômio em circuito: os percursos dos jovens e a internação psiquiátrica. Cad. Saúde Pública, 24(2), 342-352.

Yasui, S. (2011). Conhecendo as origens da reforma psiquiátrica brasileira: as experiências francesa e italiana. História, Ciências, Saúde (Rio de Janeiro), 18(2), 585-589.

Autores:

Vanessa Maurente - Doutora, Pontifícia Universidade Católica do Rio Grande do Sul.

Grace Vali Freitag Tanikado - Doutoranda, Universidade Federal do Rio Grande do Sul.

Cleci Maraschin - Doutora, Universidade Federal do Rio Grande do Sul

Endereço para correspondência:

Vanessa Maurente

E-mail: vanessamaurente@pucrs.br

Recebido em: 15.04.14

Aceito em: 11.09 .14 